\title{
Anorectal Laceration due to Crush Injury: A Case of Rarity
}

\section{Serpil Sancar, ${ }^{*}$ Esra Özçakır, Mete Kaya}

Bursa Yuksek intisas Education and Research Hospital, Turkey

\begin{abstract}
Correspondence*: Serpil Sancar, Health Sciences University Bursa Higher Specialization Training and Research Hospital, Turkey
\end{abstract}
E-mail: sancar.serpil@gmail.com

(C) 2018, Sancar et al,

Submitted: 06-08-2018

Accepted: 16-09-2018

Conflict of Interest: None

Source of Support: Nil

This is an open-access article distributed under the terms of the Creative Commons Attribution License, which permits unrestricted use, distribution, and reproduction in any medium, provided the original work is properly cited.

\section{DEAR SIR}

A 4-year old male patient met with run over injury as he fell from a moving tractor while riding. He sustained multiple injuries including laceration of right inguinoscrotal area, extending into perineum with disruption of perineal body and external anal sphincter with separation of anus. Urethra was intact but retracted deep into pelvis. Pelvic ring was disrupted and bony spicules of fracture pelvic bone were visible in the wound.(Figure 1). Hemogram and blood biochemical profile were in normal limits. Ultrasonography (US), X-rays and computed tomography (CT) revealed no intraabdominal organ injury. Fracture at the right ischio-pubic rami was noted. Urethrocystography showed type I urethral injury.

At operation, the right transverse loop colostomy was fashioned, and an antegrade washout of the distal colon performed. The tear of the rectal wall was carefully trimmed and then re-approximated with $3 / 0$ polyglycolic (Vicryl Ethicon) sutures.

External anal sphincter fibers were identified using a muscle stimulator, and repaired. A simple fixation for pelvic ring fractures was done with nylon suture. Foley catheter was retained. After operation, right leg traction was also applied. Postoperative wound healing was satisfactory (Figure 2). Urethral catheter was removed at third postoperative week.

Colostomy was closed at sixth months later. Our patient had satisfactory outcome with 1-2 bowel movements per day without soiling in between, and good urinary control.

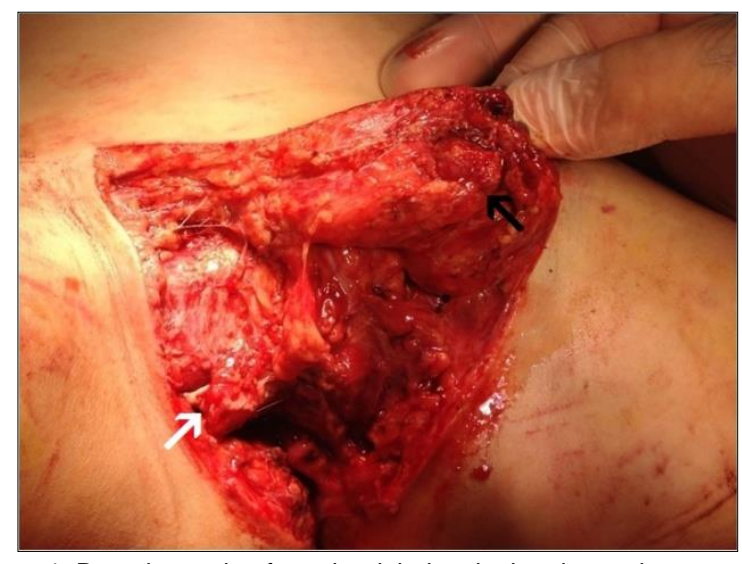

Figure 1: Deep laceration from the right inguinal region to the anus with anus pulled into the wound, ischio-pubic rami open fracture (White arrow), and scrotal skin separated (Black arrow)

The mortality rate of anorectal and genital injuries (ARGl) was higher than $67 \%$ in the past, however it has decreased in recent years to less than $10 \%$ based due to improvement in critical care services.[2,3] ARGI generally occurs in children by two mechanisms, accidents (motor vehicle trauma, firearm injury) and sexual abuse.[3] Imaging studies before surgery in patients with ARGI are controversial. Although rectal damage can be diagnosed by physical examination and proctoscopy, CT also became a helpful modality in diagnosing cranial, chest, abdominal, skeletal and other occult injuries.[4]

CT scan in our patient revealed showed no solid organ injuries. Additionally, urethrography revealed a Type I urethral injury according Goldman classification as there was intact but stretched posterior urethra.[5]. Treatment 
options for ARGI include proximal colostomy, presacral drainage, rectal defect repair, and distal rectal fecal diversion.[6] We preferred fecal diversion with right transverse loop colostomy because of the risk of infection due to severe perineal injury.

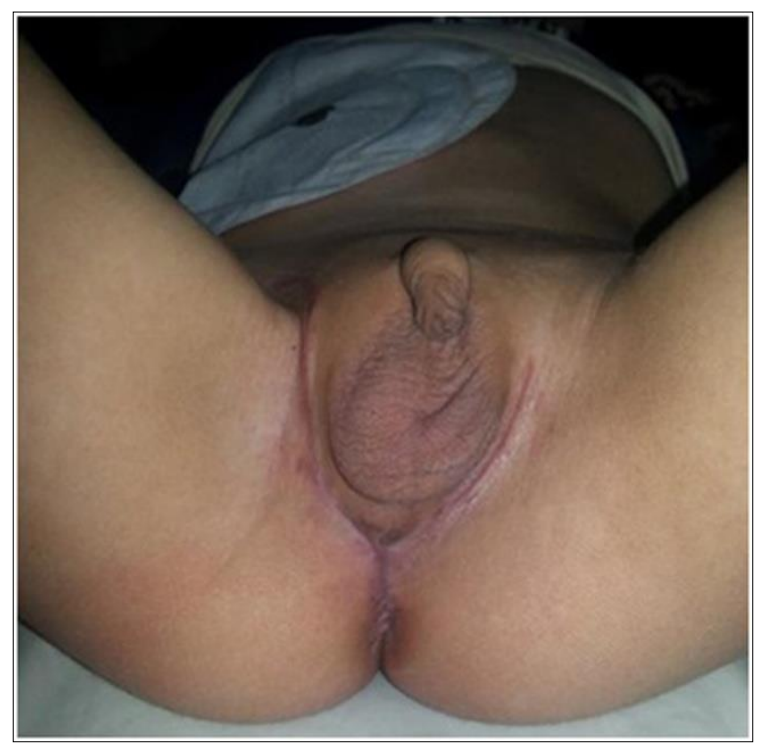

Figure 2: External appearance at 3 month postoperatively

The wound area was cleaned by antegrade enema performed from colostomy. Minor sphincter defects can be repaired primarily, but severe injuries usually require fecal diversion and sphincter reconstruction.[1-3] We used a muscle stimulator to reconstruct anal sphincters, a pelvic floor muscle and scrotal restoration were also performed in the same session. Postoperatively, the functional results and the quality of life were considered good. We are of the view that the favorable outcome is

Consent: Authors declared that they have taken informed written consent, for publication of this report along with clinical photographs/material, from the legal guardian of the patient with an understanding that every effort will be made to conceal the identity of the patient however it cannot be guaranteed

Authors' Contribution: All authors contributed equally in concept, design, literature review, drafting the manuscript, and approval of the final manuscript.

\section{REFERENCES}

1. Herzig DO. Care of the patient with anorectal trauma. Clin Colon Rectal Surg. 2012;25:210-3.

2. McGrath V, Fabian TC, Croce MA, Minard G, Pritchard FE. Rectal trauma: management based on anatomic distinctions. Am J Surg. 1998;64:1136-41.

3. OzturkH, Onen A, Dokucu Al, Otçu S, Yağmur Y, Yucesan $S$. Management of anorectal injuries in children: an eighteen-year experience. Eur J Pediatr Surg. 2003;13:249-55.

4. Leaphart CL, Danko M, Cassidy L, Gaines B, Hackam DJ. An analysis of proctoscopy vs computed tomography scanning in the diagnosis of rectal injuries in children: which is better? J Pediatr Surg. 2006;41:700-3.

5. Goldman SM, Sandler CM, CorriereJN, McGuire EJ. Blunt urethral trauma: a unified, anatomical mechanical classification. J Urol 1997;157:85-9.

6. Samuk I, Steiner Z, Feigin E, Baazov A, Dlugy E, Freud E. Anorectal injuries in children: a 20 -year experience in two centers. Pediatr Surg Int. 2015;31:815-9. 